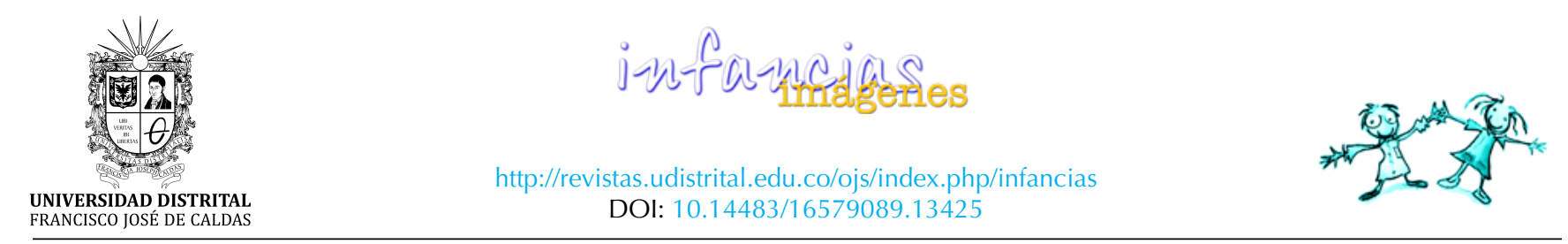

IMÁGENES DE INVESTIGACIÓN

\title{
Imaginarios de jóvenes entre 13 y 18 años acerca del ciberacoso y la empatía: un estudio de caso*
}

\author{
IImaginaries of young people between 13 and 18 years old about \\ cyberlbullying and empathy: A case study
}

\author{
Catalina Palacio Chavarriaga ${ }^{(0)}$. Leidy Jhoana Rodríguez Marín² ${ }^{(0)}$ \\ Yajaira Inés Rodríguez Cuesta ${ }^{3}$, Jessica María Giraldo Villa ${ }^{4}$
}

Para citar este artículo: Palacio, C., Rodríguez, L. J., Rodrí-

guez, Y. I. y Giraldo, J. M. (2020). Imaginarios de jóvenes

entre 13 y 18 años acerca del ciberacoso y la empatía: un

estudio de caso. Infancias Imágenes, 19(1), 21-32

\section{Resumen}

El presente artículo de investigación busca dar a conocer los imaginarios que tienen los jóvenes del grado noveno sobre el ciberacoso y su relación con la empatía. La metodología fue cualitativa, desde en un enfoque hermenéutico, y se acudió al estudio de caso como estrategia de investigación; los participantes fueron 35 estudiantes del grado noveno. Los instrumentos de recolección de información fueron: ocho entrevistas semiestructuradas; y 16 técnicas interactivas: el mural de situaciones, árbol de problemas, retablo e historias que convocan. En los resultados se observó cómo los jóvenes piensan que una sola acción en el ámbito virtual puede considerarse ciberacoso y no necesariamente debe ser repetitiva; además, ellos fueron capaces de empatizar con los diferentes actores dentro del ciberacoso. Se concluyó que es necesario desarrollar la empatía dentro de los centros educativos, para así disminuir agresiones relacionadas con el acoso y ciberacoso.

Palabras clave: acoso escolar, ambiente educacional, autoestima, relaciones entre pares.
Recepción: 2019-02-26

Aprobación: 2019-09-05

\begin{abstract}
The present research article seeks to raising awareness the imaginaries that young people of the ninth grade have about Cyberbullying and its relationship with empathy. The methodology was qualitative, from a hermeneutic approach, we went to the case study as a research strategy, the participants were 35 ninth grade students. The instruments for collecting information were: 8 semi-structured interviews and 16 interactive techniques: the mural of situations, the problem tree, the altarpiece and stories that they convene. In the results, we observed how young people think that a single action in the virtual field can be considered cyberbullying and not necessarily repetitive, and they were able to empathize with the different actors within cyberbullying. It was concluded that it is necessary to develop empathy within the educational centers, in order to reduce aggression related to bullying and cyberbullying.
\end{abstract}

Keywords: bullying, educational environment, peer relationship, self esteem.

\footnotetext{
* Artículo derivado de la investigación titulada "El imaginario de los jóvenes acerca del ciberacoso y la empatía", avalada por la Universidad Católica Luis Amigó, realizada de febrero a junio de 2018, sin financiación.

1 Licenciada en Educación Preescolar, Universidad Católica Luis Amigó. Correo electrónico: catalinapalacio3@gmail.com.

2 Licenciada en Educación Preescolar Universidad Católica Luis Amigó. Correo electrónico: leidy.rodriguezma@amigo.edu.co.

3 Licenciada en Educación Preescolar Universidad Católica Luis Amigó. Correo electrónico: yajaira.rodriguezcu@amigo.edu.co.

4 Licenciada en Educación Preescolar Universidad Católica Luis Amigó. Correo electrónico: jessica.giraldovi@amigo.edu.co.
} 


\section{Introducción}

Diferentes situaciones agresivas son experimentadas a lo largo de la vida por las personas en los múltiples contextos donde interactúan. Lo preocupante es que en los últimos años estas han cobrado la vida de muchos jóvenes en el mundo. Tanto es así que la Organización Mundial de la salud (OMS, 2016) la considera hoy como uno de los problemas de salud pública al que hay que prestar atención, dada la magnitud de las cifras de muertes violentas de personas entre los 10 y 29 años que, según su informe de 2016, Ilegó a las 200000 víctimas anuales (OMS, 2016). Cantidad alarmante si se tiene en cuenta que en la mayoría de los casos son jóvenes pertenecientes a contextos vulnerables, con escasas habilidades sociales, a quienes se les dificulta enfrentar los retos en el ambiente familiar, escolar y social donde socializan; esto los hace propensos a sufrir de problemáticas psicosociales asociadas al alcoholismo, la drogadicción, acoso escolar, ciberacoso, entre otras situaciones.

En consonancia con lo dicho, no se puede desconocer que en el ambiente escolar se configuran un conjunto de relaciones entre los diferentes actores que hacen parte de él. En algunos casos se enmarcan en agresiones físicas o verbales, catalogadas por Kowalski y Limber (2013) y Castillo y Pacheco (2008) como acoso escolar, caracterizado por ataques sistemáticos que se cometen contra una persona, específicamente en el ambiente escolar.

Por otra parte, en los últimos años el auge de las tecnologías de la información y comunicación (TIC) ha ocasionado que las hostilidades entre estudiantes trascienden del ambiente físico al ambiente virtual. Como resultado de ello surge el ciberacoso que, conforme con los postulados de Luengo (2011) y Del Rey et al. (2010), es definido como aquellas conductas agresivas que perduran en el tiempo realizadas de una persona a otra mediante diferentes aplicaciones, incluidos los diversos artefactos tecnológicos, sean estos: tableta, teléfonos inteligentes o computadores.

Ahora bien, el ciberacoso es un problema que repercute negativamente en quienes lo padecen, al generar actitudes depresivas que traen consigo sentimientos de ansiedad, estrés, miedo, inseguridad, inadaptación social y rechazo por parte de la comunidad en la que establece relaciones sociales, sea el entorno familiar, social o escolar (Sánchez et al., 2016). De estas se desprenden sentimientos de baja autoestima que conducen al que lo sufre a aislarse de sus grupos sociales y, en algunos casos, al suicidio.

Dichas consecuencias se pueden aminorar si se brindan espacios en el ambiente académico en los que los estudiantes desarrollen sentimientos de empatía, al ser considerada por Nolasco (2012) y Rifkin (2010) como factor de protección frente a situaciones hostiles en los diferentes contextos. Esto se confirma porque el tener una disposición abierta frente a las vivencias de los otros y al ser capaz de entender sus pensamientos, el victimario reacciona ante este estado emocional y hace suyo el sentimiento del otro, pensándose así mismo en dicha situación; esto lo conduce a reflexionar antes de actuar de manera inapropiada.

Así, esta investigación buscó que los jóvenes develarán sus opiniones acerca del ciberacoso que les atañe, directa o indirectamente, por el uso constante que hacen de las TIC y su relación con la empatía.

En cuanto a los imaginarios, Moscovici (cit. en Castorina, 2003), Taylor (2006) y Pinto (1995) los conceptualizan como las representaciones sociales que se forman en las personas sobre algún aspecto de la vida, una vez ha pasado por los sentidos así sea de forma poco detallada. Con el tiempo, se convierten en imaginarios primero individuales para luego ser compartidos socialmente dentro de la comunidad en la que el sujeto socializa.

De todo lo dicho hasta el momento surgió el interés por investigar sobre el ciberacoso, como una forma de dar respuesta a las pocas investigaciones que se han encontrado en el ámbito académico local sobre este problema desde las concepciones que tienen los estudiantes en sus interacciones cotidianas. En este sentido, se realizó un estudio de corte cualitativo en una institución educativa pública de la ciudad de Medellín. Allí se pretendió comprender los imaginarios que poseen los estudiantes de noveno grado acerca del ciberacoso y su relación con la empatía, al ser una situación propia de personas ubicadas en edades entre los 10 y 16 años, según lo planteado por Sanabria (2014). Por 
lo tanto, el objetivo del presente artículo es dar a conocer los resultados de la investigación, con el propósito de sensibilizar a los docentes y estudiantes para prevenir o disminuir el acoso virtual.

Antes de iniciar la recolección de información se realizó una encuesta de caracterización, en la cual se evidenció que la mayoría de los estudiantes utilizan internet más de una hora diaria e interactúan por medio de las redes sociales, exponiéndose a todas las situaciones positivas y negativas que allí se enmarcan, entre ellas el ciberacoso.

\section{Metodología}

Esta investigación es de corte cualitativo. Este es definido por Martínez (2006) como un proceso sistemático que busca comprender la realidad desde la perspectiva de los participantes. Además, se enmarca en un enfoque hermenéutico, definido por Gadamer (1996) como una manera de comprender la historia a partir de las concepciones que tienen los individuos.

\section{Participantes}

La institución educativa fue elegida porque se tenía contacto con el rector y algunos docentes, quienes evidenciaron que existían problemas de ciberacoso en el grado noveno. Posteriormente, se seleccionaron 35 estudiantes para participar del proyecto de investigación, debido a que cumplían con los siguientes criterios de selección: edades entre 13 y 18 años, usar redes sociales, conocer casos de ciberacoso y estar en noveno grado.

En cuanto a los aspectos éticos se solicitó la firma del consentimiento informado por parte de los padres de familia y el asentimiento a los estudiantes elegidos para este estudio, asimismo se les dio a conocer la forma como se analizarían los datos obtenidos.

\section{Herramientas}

Luego de realizar el rastreo de antecedentes sobre el problema en cuestión, se socializó al rector el proyecto y las herramientas que serían utilizadas para la recolección de información. Posterior a su aprobación, se expuso a los estudiantes del grado noveno dos, quienes aceptaron ser parte de la investigación.

Para facilitar la recolección de información y la aplicación de los instrumentos se dividió el grupo de 35 estudiantes en subgrupos de ocho; cada uno fue coordinado por una investigadora. Se utilizaron cuatro técnicas interactivas en cada uno de los subgrupos, para un total de 16; estas fueron: mural de situaciones, historias que convocan, retablos y el árbol de problemas. Estas técnicas fueron definidas por Quiroz et al. (s. f.) como el conjunto de acciones e instrumentos que permiten recolectar, analizar y validar información; bajo condiciones especiales, que dan la posibilidad de recuperar experiencias, para construir conocimiento.

De otro lado, se seleccionaron ocho estudiantes para realizar entrevistas semiestructuradas, debido a que en el desarrollo de las técnicas interactivas se evidenció que habían sufrido de ciberacoso o conocían casos cercanos. Este instrumento es definido por Kvala como una forma de "obtener descripciones del mundo de la vida" (cit. en Álvarez, 2015, p. 109) al dar la posibilidad de comprender la manera como los participantes de la investigación conciben dicho problema.

\section{Procedimiento}

En el análisis de los datos obtenidos lo primero que se hizo fue depurar la información recolectada de cada subgrupo. Para esto se utilizó una matriz inicial, con el fin de clasificarla según las categorías del proyecto; posteriormente se elaboró una matriz de unificación. A continuación, en la tabla 1 se muestra un ejemplo.

La tabla anterior es un ejemplo de la matriz que fue utilizada para analizar la información recolectada durante la investigación, en la aplicación de cada una de las técnicas, en los relatos de los estudiantes surgen subcategorías (sentimientos, burlas, factores de protección). Estas se resaltaron con diferentes colores para observar las ideas repetidas conforme a las concepciones de los participantes; posteriormente, las investigadoras realizaron comentarios a estos, contrastándolos con la teoría para analizarlos y llegar a las conclusiones. 
Tabla 1. Matriz de unificación

\begin{tabular}{|c|c|c|}
\hline Categorías & Enunciados de referencia & Comentarios \\
\hline Categoría: ciberacoso & ¿Para ti que es el ciberacoso? & \multirow{4}{*}{$\begin{array}{l}\text { En las diferentes respuestas de los estudiantes, } \\
\text { muchos de ellos coinciden con Del Rey et al. } \\
\text { (2010) quienes afirman que el ciberacoso es una } \\
\text { agresión que se hace por medio de las (TIC). }\end{array}$} \\
\hline Técnica n. ${ }^{\circ} 1$ Mural de & Respuesta participante \# 8 (Juliet-Yelena): Cuando & \\
\hline Subcategorías: & sociales cosas que no se deben poner, por envidia & \\
\hline 1.Burla & Respuesta participante $n .^{\circ} 18$ : & \\
\hline 2.sentimientos & "el ciberacoso es cuando a una persona le hacen & \multirow{6}{*}{$\begin{array}{l}\text { Sandin (1967) afirma que "Las emociones tienen } \\
\text { sentido somático e inconsciente, el sentimiento } \\
\text { tiene sentido psíquico consciente" es decir, el } \\
\text { primero es algo que se manifiesta inconsciente- } \\
\text { mente ante un estímulo ya sea externo o interno, } \\
\text { y el segundo implica pensar y reflexionar cons- } \\
\text { cientemente sobre lo que se está sintiendo, este } \\
\text { último se prolonga en el tiempo en la mente y } \\
\text { en el cuerpo. }\end{array}$} \\
\hline 3.Factores protectores & $\begin{array}{l}\text { bullying a alguien por un chat o sitio web en la } \\
\text { cual pueda llegar a incomodar a quien lo sufre". }\end{array}$ & \\
\hline Categoría & & \\
\hline Técnica n. ${ }^{\circ} 2$ : retablo & ¿Qué papel te tocó dramatizar y cómo te sentiste & \\
\hline Subcate & & \\
\hline Sentimic & $\begin{array}{l}\text { Respuesta de la participante } n .^{\circ} 22 \text { : } \\
\text { "El victimario. Fue divertido, pero luego quedé im- } \\
\text { pactada, pensando en las personas que realmente } \\
\text { son de esa manera y que se toman el tiempo para }\end{array}$ & \\
\hline & hacerle daño a otra". & \multirow{3}{*}{$\begin{array}{l}\text { Luengo, (2011) define el ciberacoso como una } \\
\text { "agresión psicológica sostenida y repetida en el } \\
\text { tiempo, perpetrada por uno o varios individuos } \\
\text { contra otros, utilizando para ello las nuevas tec- } \\
\text { nologías." (p. 12). Lo cual es similar a lo expresa- } \\
\text { do por el participante n. }{ }^{\circ} 29 \text { en su relato. }\end{array}$} \\
\hline $\begin{array}{l}\text { Categoría: imaginarios } \\
\text { este concepto transversa- } \\
\text { liza todos los relatos }\end{array}$ & $\begin{array}{l}\text { ¿Cuál cree usted que son las características que } \\
\text { debe cumplir una situación para ser considerada } \\
\text { como ciberacoso? }\end{array}$ & \\
\hline Técnica n & $\begin{array}{l}\text { Respuesta del participante } \text {. }^{\circ} 29 \text { : "en vez de ser } \\
\text { físico y verbal, sea por medio electrónico y de for- }\end{array}$ & \\
\hline Categoría: acoso escolar & $\begin{array}{l}\text { ¿Cuáles creen que son las diferencias entre el aco- } \\
\text { so y el ciberacoso? }\end{array}$ & \multirow{6}{*}{$\begin{array}{l}\text { En la actualidad, el uso de internet es común en } \\
\text { los adolescentes quienes se comunican más por } \\
\text { medios electrónicos, donde se crean nuevos am- } \\
\text { bientes de socialización, en los que se pueden } \\
\text { Ilevar a cabo conductas agresivas. Como lo dice } \\
\text { Del Rey et al. (2010) la violencia rompe la ba- } \\
\text { rrera de lo físico y se traslada a lo virtual donde } \\
\text { tiene mayor repercusión. }\end{array}$} \\
\hline Técnica n. ${ }^{\circ}$ 4.: historias & Respuesta del participante n. ${ }^{\circ} 16$ : & \\
\hline que convocan & & \\
\hline $\begin{array}{l}\text { Subcategoría } \\
\text { 1.Burla }\end{array}$ & $\begin{array}{l}\text { cuencias psicológicas y no se puede hacer física- } \\
\text { mente; mientras que en el colegio se hace acoso }\end{array}$ & \\
\hline 2. Sentimientos & físico. Cuando se hace a través de las redes, es & \\
\hline 3. Factores de protección & $\begin{array}{l}\text { mucho más difícil detenerlo porque se dan cuenta } \\
\text { muchas personas." }\end{array}$ & \\
\hline
\end{tabular}

Fuente: elaboración propia de las autoras.

\section{Resultados y discusión}

A continuación, se detallan los resultados del proyecto de investigación relacionados con las categorías ciberacoso, acoso escolar y empatía. Cabe aclarar que la categoría imaginarios estará inmersa durante el desarrollo de este apartado al resaltar la manera de pensar que tienen los jóvenes sobre el tema en cuestión.

\section{Diferencias conceptuales de los términos acoso y ciberacoso desde las voces de los jóvenes de noveno grado}

A través de las técnicas de recolección de información los estudiantes dieron distintos argumentos con respecto a las diferencias entre el acoso escolar y el ciberacoso. Muchos de ellos coinciden con Del Rey et al. (2010), pues conciben el ciberacoso como una agresión que se hace por medio de las TIC. Al respecto, el participante n. ${ }^{\circ} 24$ expresó:

Cuando una persona tiene miedo de decirle las cosas a alguien personalmente o hacerle acoso directamente, simplemente lo hace por las redes sociales, y expresan su odio, agresión, se divierten por este medio, porque no eres capaz de hacerlo en persona. (Entrevista realizada el 20 de marzo de 2018)

De igual forma, Sánchez et al. (2016) afirman que el ciberacoso es la manera como se agrede a una persona mediante artefactos tecnológicos $y$, 
además, se presenta de forma reiterada. Algunos de los participantes piensan en el concepto como la acción de molestar a las personas, pero en el ámbito virtual. Así mismo, Ortega et al. (cit. en Morales et al., 2014) lo definen como "una agresión intencional, por parte de un grupo o un individuo, usando formas electrónicas de contacto, repetidas veces, a una víctima que no puede defenderse fácilmente por sí misma" (p. 25). En relación con esto, algunos participantes del estudio refirieron:

Ciberacoso es la cobardía a través de una pantaIla. (Participante n. ${ }^{\circ} 33$, técnica interactiva mural de situaciones realizada el 26 de febrero de 2018)

El ciberacoso es cuando a una persona le hacen bullying a alguien por un chat o sitio web en el cual pueda llegar a incomodar a quien lo sufre. (Participante $\mathrm{n} .^{\circ} 18$, técnica interactiva mural de situaciones realizada el 26 de febrero de 2018)

Aquí se confirma que los imaginarios de los jóvenes acerca del ciberacoso se asemejan a los de Del Rey et al. (2010), Morales et al. (2014) y Sánchez et al. (2016); al tener claras las diferencias, características y posibles consecuencias de estas conductas. Sin embargo, se debe tener en cuenta que los jóvenes se basan en sus conocimientos previos, a partir de su experiencia, y los teóricos fundamentan sus afirmaciones en investigaciones, realizadas por ellos y otros autores.

Igualmente, se tiene en cuenta la definición del acoso escolar desde la Fundación Santillana para Iberoamérica, la cual lo refiere como "cualquier forma de maltrato psicológico, verbal o conductas relacionadas, que ocurren de manera continuada y deliberada, entre estudiantes [...]" (2012, p. 35). En relación con esto, el participante $n .^{\circ} 29$ expresa:

Es ofender, agredir a las personas verbal y físicamente, diciéndoles insultos de manera repetitiva y en persona. (Entrevista realizada el 15 de marzo de 2018)

Por otro lado, los jóvenes coinciden con Instituto Interamericano de Derechos Humanos (2014), al referir que "el acosador lo ejerce con el propósito de hacer daño y humillar a sus víctimas" ( $p$. 194). Al respecto, el participante $n .^{\circ} 24$ describe la finalidad del acoso escolar de la siguiente manera:

Es que alguien acosa a otro para humillarlo. Que tenga mucha intención de hacer el daño y que este sea repetido. (Entrevista realizada el 17 de marzo de 2018)

En contraste con lo anterior, lo que conlleva al victimario a realizar este tipo de conductas puede ser: tenerle envidia a la víctima, que esta no sea de su agrado, querer llamar la atención o sentirse superior (Luengo, 2011). A continuación, el participante n. ${ }^{\circ} 6$ relata lo siguiente en relación con el acoso escolar:

El acoso escolar se hace por envidia, porque la quiere molestar, por llamar la atención, para hacerle la vida imposible, no dejarla vivir, llevarla a la depresión y en algunos casos hasta el suicidio. (Entrevista realizada el 13 de marzo de 2018)

Ahora bien, para establecer las diferencias que plantean los estudiantes entre el acoso escolar y el ciberacoso, ellos en sus respuestas expresan que el ciberacoso presenta comportamientos comunes con el acoso escolar, y enfatizan que la diferencia son los espacios físicos o virtuales en que se desarrollan dichas conductas. Los jóvenes resaltan:

Yo creo que el acoso escolar se da en el colegio, y el ciberacoso es propagar eso que pasa en la escuela por internet. (Participante n. ${ }^{\circ}$, entrevista realizada el 20 de marzo de 2018).

Ciberacoso es de los medios tecnológicos, redes sociales tomarles fotos a otras y acoso es cuando yo te tengo en frente y te digo cosas feas; hay muchos tipos de acoso, pero el ciberacoso es más que todo por medio de la tecnología. (Participante n. ${ }^{\circ} 36$, entrevista realizada el 12 de marzo de 2018).

Estas respuestas o percepciones dadas por los jóvenes sobre el acoso escolar y el ciberacoso se relacionan con acciones cuyo propósito es perjudicar en las redes sociales a alguien, ya sea con burlas, bromas o fotos que afecten la integridad de una persona. Dicho de otra forma, el acosador selecciona a su víctima y en reiteradas ocasiones 
realiza conductas agresivas en contra de ella, ocultándose en la red (Instituto Interamericano de Derechos Humanos, 2014). Estas pueden darse en el acoso escolar, con la diferencia de que se realiza en espacios físicos y pueden trascender a lo virtual. Por consiguiente, para los jóvenes el ciberacoso es atacar al otro, refugiándose detrás de una pantalla sin pensar en el daño y en las consecuencias a nivel físico y psicológico.

En resumen, los participantes conocen las diferencias que existen entre acoso escolar y ciberacoso. Es así como en el desarrollo de las técnicas y en sus respuestas se pudo evidenciar la claridad que tienen acerca de ambos conceptos, sus características y las consecuencias que trae consigo la réplica de dichas conductas. De otro lado, en algunos relatos los jóvenes manifiestan su inconformidad con las personas que usan las redes sociales para agredir y humillar a otros. No obstante, en la mayoría de los casos los participantes no son conscientes de cómo repercuten sus acciones en este tipo de actos, por lo que se perciben a sí mismos como espectadores de la problemática y no como agentes reforzadores de las conductas del acosador (Luengo, 2011).

\section{El hostigamiento, el sexting y la denigración:} clasificaciones del ciberacoso desde el punto de vista de los participantes

Antes de ahondar en este tema es necesario saber que existen las siguientes clasificaciones del ciberacoso: provocación incendiaria, suplantación de la identidad, exclusión, hostigamiento, sexting y denigración (Willard, cit. en Morales et al., 2014). Sin embargo, durante la aplicación y recolección de información únicamente surgieron tres tipos: el hostigamiento, el sexting y la denigración; los cuales se evidenciaron en los relatos de los jóvenes que más adelante se encontrarán, ya sea como víctimas o espectadores de la situación por el uso habitual de las redes sociales, que en algunas ocasiones se les da un uso inadecuado.

En primer lugar, se hablará del hostigamiento. Este es definido por Willard como:

Mensajes con contenidos ofensivos por los medios electrónicos escritos o de tipo visual y distribuir información despectiva y falsa de una persona; por ejemplo, colgar fotografías alteradas digitalmente que muestren a la persona en situaciones comprometedoras, inventar rumores que afecten la reputación de una o varias personas, burlas sobre la orientación sexual, discapacidades u origen étnico, etc. (cit. en Morales et al., 2014, p. 40).

En relación a esto, un joven expresó lo siguiente:

Para mí el ciberacoso es como molestar a una persona, estar ahí encima de ella, diciéndole cosas, denigrándola, o hasta sin decirle nada lo afecta directamente acosándolo, como hace esa gente que crea perfiles falsos para estar ahí diciéndoles cosas a las personas. (Participante . $^{\circ}$ 36, entrevista realizada el 20 de marzo de 2018).

Se puede ver cómo el participante expresa algunas de las características mencionadas anteriormente, asociadas con el hostigamiento como los mensajes ofensivos, el publicar fotografías editadas, con falsos comentarios, los cuales buscan dañar la imagen de la persona frente a su grupo de amigos. En muchas ocasiones estas conductas se normalizan en las interacciones de los adolescentes ignorando su verdadera dimensión y gravedad.

En este sentido, se infiere que el imaginario de los jóvenes respecto a las concepciones que poseen relacionadas con las nociones de acoso escolar y ciberacoso se acerca a lo que plantean Morales et al. (2014), relacionado con las características específicas del ciberacoso.

En segundo lugar, en cuanto a las acciones de burla, divulgadas en los medios electrónicos, Morales et al. (2014) las clasifican dentro de una categoría denominada denigración. Todo este tipo de contenidos pueden molestar $\mathrm{u}$ hostigar a quienes los reciben, trayendo como consecuencias: odio, rencor, deseos de vengarse, rabia, aislamiento e incluso suicidio. De este modo, la denigración se reconoce como la difusión de rumores y fotografías falsas, acerca de una persona en situaciones comprometedoras con el fin de perjudicar su imagen.

En relación a esta clasificación, se evidencia el siguiente relato: 
En el ciberacoso se dan una serie de burlas que se generan hacia una persona por medio de internet y todo puede empezar ya sea por rabia, por broma, por un fotomontaje, entre otros. (Participante n. ${ }^{\circ} 27$, técnica interactiva mural de situaciones realizada el 26 de febrero de 2018)

Allí se ve cómo el imaginario de los jóvenes se acerca a los postulados de los autores, al ser una de las clasificaciones que más se evidenció en sus comentarios durante la realización de las técnicas aplicadas para la recolección de información; debido a que todos coinciden en que una de las características del ciberacoso está asociada con la burla, la cual se relaciona con los mensajes despectivos que se realizan hacia la víctima.

Por último, se tiene al sexting, el cual consiste en la difusión de imágenes que incluyen contenido sexual explícito. Definido por Morales et al. como:

Utilizar imágenes de actos sexuales privados que fueron grabados, con el consentimiento o no de la víctima, para difundirlas en espacios públicos de la Red. Se da por lo general entre adolescentes que tuvieron una relación amorosa que concluyó en una ruptura. (2014, p. 40)

En el siguiente testimonio se da a conocer un caso relacionado con esta clasificación:

Yo era amiga de una muchacha en otro colegio, ella tenía un novio, y le mandaba fotos desnuda. Un día él las difundió y todos los compañeros del colegio la vieron y empezaron a hacerle comentarios sexuales, ella entró en tanta depresión y desesperación que decidió quitarse la vida. (Participante n. ${ }^{\circ} 11$, entrevista realizada el 13 de marzo de 2018)

Cabe resaltar que, según lo observado en las redes sociales, al parecer el sexting es un hecho común entre los jóvenes y adolescentes, quienes confían en determinadas personas para revelar fotos de su intimidad, pero que se hacen públicas por chantaje o venganza cuando se deteriora la relación entre ambas partes. Dicha situación en ocasiones genera sentimientos de vergüenza, desesperación y baja autoestima en quien lo sufre. Además, el desenlace puede ser trágico y lamentable, como en el caso anterior y en el siguiente testimonio.

A una joven que era muy alegre la acosaron sus compañeros por mucho tiempo, haciéndole Photoshop a sus fotos y publicándolas desnuda en las redes sociales, por esto ella cambió radicalmente, no soportó esta situación y se suicidó. (Participante n. ${ }^{\circ} 24$, entrevista realizada el 13 de marzo de 2018)

En relación con este tipo de consecuencias existe la sentencia T-478/15 de la Corte Constitucional, en cuanto al caso del joven Sergio David Urrego, quien se suicidó debido al acoso de sus compañeros por sus preferencias sexuales.

De allí surge la necesidad de capacitar en estos temas a los docentes y adultos que instruyen a los jóvenes, con el fin de prepararlos para orientar asertivamente los procesos de socialización en el ámbito virtual y generar actitudes de prevención y protección alrededor de esta problemática.

Finalmente, es importante aclarar que las definiciones y características de estos tipos de ciberacoso, según los diferentes autores, no están manifestadas de forma explícita en los relatos de los participantes; debido a que ellos desde su imaginario y experiencia expresan las características de cada clasificación. Por lo que puede decirse que esta situación no es ajena a la cotidianidad de los participantes quienes socializan en los medios virtuales.

\section{Los jóvenes y su empatía ante situaciones de ciberacoso}

En la actualidad las interacciones sociales han superado los espacios físicos, trasladándose en algunas oportunidades hacia lo virtual. Sobre todo en los jóvenes, debido a que tienen fácil acceso a información que llega de muchos rincones del mundo simultáneamente en forma de videos, imágenes, fotos, audios, entre otros formatos a través de la web. Esto produce en los internautas sentimientos de empatía, que pueden ser iguales a los que otros tienen al verlos u oírlos. Asimismo, las relaciones interpersonales y el contacto que se solía tener se ha modificado y genera la necesidad del uso de emoticones, para dar sentimiento al 
mensaje frio que se puede transmitir por medio de un ordenador.

Los participantes demostraron sus sentimientos empáticos frente a diferentes videos que le fueron proyectados y dramatizaciones realizadas durante la aplicación de las técnicas de recolección de información sobre las problemáticas del ciberacoso. Estas consistían en que los participantes debían asumir el papel de acosadores, víctimas, espectadores o defensores de los acosados y acosadores.

En este sentido, Hoffman define la empatía como "los procesos psicológicos que hacen que una persona tenga sentimientos más congruentes con la situación de otra persona que con la suya propia" (cit. en Rifkin, 2010, p. 18). Es decir, a pesar de que las situaciones de ciberacoso pueden ser cercanas a la vida de los jóvenes, pueden emerger en ellos sentimientos de empatía hacia los implicados en este.

Sin embargo, algunos de los jóvenes demuestran que les cuesta ser empáticos con el acosador, al considerar que realizan conductas inapropiadas. La gran mayoría ignora el motivo en el que se resguarda el victimario de esta situación para realizar dichas acciones. Esto se evidencia en el siguiente relato:

No soy capaz de ponerme en el lugar del acosador ni del espectador porque no entiendo el motivo que tienen para hacer eso. (Participante n. ${ }^{\circ} 11$, entrevista realizada el 13 de marzo de 2018)

De esto se puede inferir que los jóvenes consideran que es una conducta reprochable. Por esta razón, niegan que puedan estar en el lugar del acosador o el espectador al reconocer de forma implícita que actúan de forma inapropiada.

En contraste con este comentario, el participante n. ${ }^{\circ} 29$ expresa:

El acosador es feliz al ver que el otro sufre, pero la verdad sería bueno preguntarse por el motivo de su agresión. (Entrevista realizada el 23 de marzo de 2018)

En estos comentarios se evidencian las diferentes posiciones que tienen los participantes acerca del acosador cuando realiza dichas conductas; en algunas ocasiones mostraron su inconformidad frentes a este tipo de actos. En este punto es importante reflexionar sobre los motivos que tiene el acosador para realizar ciberacoso; los cuales, conforme a lo propuesto por Del Rey et al., pueden ser: "la envidia, el no poseer normas del uso de internet, tener baja tolerancia a la frustración, justificar la violencia, especialmente la indirecta, abuso de poder" (2010, p. 20).

Uno de los jóvenes expresa las posibles causas que motivan un acosador:

Lo hace por diversión, inseguridad, por venganza, porque creció en un lugar lleno de violencia y piensa que así se puede expresar o simplemente para llamar la atención o también ser popular. (Participante $\mathrm{n}$ $^{\circ}$ 24, entrevista realizada el 20 de marzo de 2018)

Se observa en el relato cómo los jóvenes manifiestan que los motivos por los cuales un acosador realiza estas prácticas están relacionados con los sentimientos del acosador, tales como: rabia, tristeza, soledad, venganza, deseo de llamar la atención u odio. Esto podría demostrar que los participantes al estar directamente implicados en esta problemática como víctimas, victimarios o espectadores la conocen de cerca y reconocen sus características sin estudiarla a profundidad.

De otro lado, al reflexionar desde el punto de vista de la víctima, Latorre y Muñoz mencionan que "las víctimas de estos ataques son crónicamente inquietos, tanto en su propia casa como en el colegio, con una autoestima baja, excluidos por el grupo de pares, de apariencia física débil y temerosos de repeler la ofensa" (2001, p. 11). Al respecto, un participante expresó que la mayoría de veces:

En el ciberacoso se coge al más débil, al que tiene gustos diferentes al otro. (Participante n. ${ }^{\circ} 4$, técnica interactiva historias que convocan realizada el 5 de marzo de 2018)

En este relato se evidencia cómo los imaginarios de los participantes coinciden con los autores en las características que busca el victimario para agredir a su víctima, entre ellas: la fragilidad, la incapacidad para defenderse y la debilidad en 
el carácter. Por ende, es necesario dárselas a conocer a los jóvenes con el propósito de fortalecer su temperamento para que de este modo sean menos vulnerables frente a situaciones de ciberacoso. Igualmente, durante del desarrollo de la investigación, en la mayoría de los relatos se observó la empatía de los adolescentes con los acosados. El siguiente relato es una prueba de esto:

Las víctimas pueden sentir dolor y preguntarse ¿por qué esto me pasa a mí? ¿Yo qué hice para merecerlo? Más que todos esos pensamientos; también piensan en el suicidio, y casi siempre se lo callan por sentir vergüenza o porque creen es su problema. (Participante n. ${ }^{\circ} 24$, entrevista realizada el 20 de marzo de 2018)

En este relato el participante demostró ser capaz de ponerse en el lugar de la víctima, a diferencia de lo que se mencionó anteriormente en relación con el victimario, con quien es más difícil sentir empatía. Al respecto, Rifkin (2010) expresa que la empatía deja de ser un sentimiento particular gracias a las redes sociales y se convierte en un sentimiento global, que en algunas ocasiones propicia la solidaridad entre los seres humanos, incluso con personas desconocidas. Allí se observa un cambio de imaginario en relación con la empatía en la actualidad al dejar de ser individual y convertirse en pública por medio de las redes sociales.

Otro de los papeles desarrollado dentro de las actividades de recolección de información fue el de espectador. En él los jóvenes tomaron una actitud activa o pasiva al momento de ser testigos de una situación de ciberacoso. Con relación a esto, Rifkin (2010) presenta la empatía no solo desde la capacidad de compadecerse con el victimario sino, también, por la capacidad que tienen aquellos que son testigos de tomar parte de esa experiencia dentro de sí mismos de manera indirecta. Es decir, al observar pasivamente estas conductas ellos son partícipe de dicha situación, de tal forma que influye en la conducta del acosador porque uno de sus objetivos es llamar la atención de su círculo social; por consiguiente. esto lo incentiva para que siga realizando acciones de ciberacoso.

En la voz de uno de los jóvenes se evidencia lo anterior:
Me tocó el papel de espectador y me sentí mal por la persona acosada porque sé que no se sentía bien al ver que yo no hacía nada. (Participante n. ${ }^{\circ}$ 18, técnica interactiva retablo realizada el 12 de marzo de 2018)

Desde otra perspectiva, los participantes que fueron espectadores y a su vez víctimas de ciberacoso refieren ser indiferentes ante estas circunstancias, porque no sintieron apoyo por parte de las personas que estuvieron presentes cuando sufrieron dicha situación. Esto se reafirma en el siguiente comentario:

Como dije no tengo empatía, la verdad no siento que deba hacer algo, si está pasando por un momento así, que esa persona resuelva sola su problema. (Participante n. ${ }^{\circ} 33$, entrevista realizada el 20 de marzo de 2018)

Durante la realización de esta entrevista se comprende cómo los espectadores llegan a ser entes pasivos por miedo a involucrarse directamente con esta problemática, bien sea defendiendo a la víctima o por el hecho de interferir en las conductas de agresión. Deciden mejor no actuar cuando son testigos de acoso en el ámbito virtual, debido al temor que genera la transición de espectadores a víctimas.

Por otra parte, los jóvenes consideran que las conductas como grabar un vídeo, difundirlo o avivar los ánimos influyen en la vida del afectado y no lo perciben como algo normal en las interacciones sociales que se dan en la virtualidad; sin embargo, continúan haciendo uso inadecuado de las redes sociales. A pesar de esto se observan algunas situaciones específicas en las cuales los jóvenes no son capaces de sentir empatía por la victima de ciberacoso, como lo expresó el participante n. 33.

De esta manera, se observan las conductas empáticas que poseen los jóvenes con los partícipes del ciberacoso, sean estos víctimas, victimarios o espectadores; al coincidir con los sentimientos de tristeza y culpa por estar haciendo las cosas mal, no poder defender a la víctima por medio de mensajes de apoyo a ella y ayudarla a cambiar su situación. A su vez, coinciden en que es una circunstancia común y cercana a ellos. 
En síntesis, uno de los aspectos que surge como posible alternativa para prevenir situaciones de acoso o ciberacoso es reflexionar sobre las acciones antes de actuar y ser capaz de pensar cómo se sentiría esa persona al ser víctima de tal agresión y, más aún, cómo se sentiría el acosador, si él fuera el perjudicado por este flagelo.

Autoestima: un sentimiento afectado por el ciberacoso

Esta categoría emerge de forma transversal en la aplicación de las técnicas de recolección de información en los relatos de los jóvenes, por lo que es importante hacer mención de ella. Esta es, según Bermúdez "la representación mental que tiene una persona de sí misma" (2004, p. 19). Dicho de otra forma, es lo que cada uno piensa en relación con su apariencia, el amor y la valoración que se tiene; la baja autoestima es el conjunto de sentimientos negativos del sujeto sobre sí mismo. Esto se relaciona con la clasificación del ciberacoso, denominado denigración, porque las burlas que se realizan a una persona sobre sus publicaciones en las redes sociales pueden llevar a que el sujeto se cree una imagen errónea de sí mismo.

En este punto se ve cómo el ciberacoso trae consecuencias para las víctimas, algunas de ellas mencionadas por Sánchez et al. como: "ansiedad, depresión, baja autoestima, estrés, miedo, sentimientos de ira, frustración [...] Para tratar de aliviar estos síntomas, algunas víctimas recurren a conductas inadecuadas como el consumo de alcohol, marihuana o medicamentos no prescritos" (2016, p. 38). Por tanto, aunque el ciberacoso es una problemática que se ve en gran medida en los centros educativos no es un tema ajeno a otros ambientes en los que socializan los jóvenes, como lo son su barrio, la familia, los medios de transporte, etc.

Adicionalmente, los participantes están de acuerdo con Sánchez et al. (2016) en que la baja autoestima es una consecuencia del ciberacoso. Esto se puede evidenciar en el siguiente relato:

Hemos visto casos de personas que presentan baja autoestima cuando les hacen ciberacoso y a causa de esto se pueden suicidar. (Participante n. ${ }^{\circ}$

32, entrevista realizada el 20 de marzo de 2018)

De la voz del joven se infiere cómo el ciberacoso perjudica el diario vivir de sus protagonistas, en cuanto a la socialización en su ambiente escolar; en muchas puede desencadenar conductas depresivas, deterioro físico y emocional, aislamiento social e incluso situaciones extremas como el suicidio (Escobar et al., 2016). Respecto a esto, un participante expresó:

El ciberacoso puede causar aislamiento; se van y se apartan de las personas y se vuelven depresivas, pueden llegar a causar el suicidio. (Participante n. ${ }^{\circ}$ 35 , técnica interactiva árbol de problemas realizada el 16 de marzo de 2018)

En el relato se evidencia la percepción de los participantes en relación con el sentir de los involucrados en el ciberacoso; allí se presentaron sentimientos como tristeza, alegría, impresión e indiferencia. Estos, desde la perspectiva de Sandín, están relacionados con: "las emociones que tienen sentido somático e inconsciente y el sentimiento tiene sentido psíquico consciente" (1967, p. 45). Es decir, el primero (emociones) es algo que se expresa corporalmente ante determinada experiencia de forma impulsiva sin pasar por la razón; el segundo (sentimientos) también se manifiesta desde la corporeidad, pero implica pensar sobre lo que se está sintiendo, por lo que se prolonga en el tiempo al pasar por la razón, facilitando la reflexión de lo que se está haciendo.

Este tipo de emociones deben ser canalizadas con el fin de no generar un daño irremediable tanto para la víctima como para el acosador. En este sentido, Goleman (1996) insiste en la necesidad de reconocer nuestras propias emociones y saber cómo reaccionar respecto a ellas para no actuar equivocadamente o quedarse permanentemente en dicha emoción. Por esta razón deben ser gestionadas de la mejor manera para cumplir con su verdadero propósito y no estancarse en una situación que puede perjudicar tanto a nivel personal como interpersonal e incluso facilitar conductas de ciberacoso o agresión. 
En definitiva, los sentimientos juegan un papel importante en cuanto a la supervivencia y el bienestar de las personas. Por esto, la educación emocional debe tomar relevancia al interior de la escuela, con el fin de servir como factor de protección frente a situaciones de ciberacoso.

\section{Conclusiones}

El ciberacoso es definido como una agresión que se hace por medio de TIC (Del Rey et al., 2010). Al respecto, los participantes durante la aplicación de los instrumentos demostraron estar de acuerdo con estos autores y tener un conocimiento acerca de la situación objeto de estudio, sus características y las consecuencias que trae consigo la réplica de dichas conductas. Además, tienen claridad a la hora de reconocer las diferencias entre el acoso escolar y el ciberacoso, al identificar claramente los espacios donde se desarrollan ambas problemáticas.

Acorde con lo dicho, en la actualidad el uso de internet como medio de comunicación y diversión es muy común en los adolescentes y genera nuevos ambientes de socialización acompañados de nuevas problemáticas. En este sentido, es necesario categorizar el ciberacoso porque no todas las conductas refieren a los mismos patrones de agresión, según lo explican Del Rey et al. (2010). En los relatos de los participantes se evidenciaron los tipos de ciberacoso relacionados con: la denigración, el hostigamiento y el sexting. Allí se confirma que la web es un espacio en el cual se llevan a cabo conductas agresivas. Tal como lo plantea Del Rey et al. (2010), la violencia rompe la barrera de lo físico trasladándose a lo virtual, por lo tanto, es más difícil detener las agresiones debido a que llegan a muchas personas de forma simultánea y ocasiona un daño irreversible.

De otro lado, Rifkin (2010) considera que la empatía se convierte en un sentimiento global gracias al uso de las redes sociales ya que, a través de ellas, muchas personas pueden presenciar situaciones que viven otros individuos en diferentes partes del mundo. Tales hechos generan múltiples reacciones entre los espectadores: una de ellas es la empatía, que permite ponerse en el lugar del otro. En los relatos de los jóvenes se logró evidenciar cómo ellos llegaron a reflexionar sobre el ciberacoso de manera profunda y comprendieron que este se encuentra relacionado con los sentimientos de empatía y autoestima que les permite prevenir este tipo de conductas tanto en el contexto escolar como en la web.

A su vez, se pudo observar que el empatizar con el otro es una posible alternativa para prevenir situaciones de acoso o ciberacoso; es decir, ponerse en el lugar del otro evitaría el desarrollo de estas conductas poco empáticas. De esta forma, si se tiene en cuenta que la empatía hace parte del conjunto de habilidades que se desarrolla dentro de la inteligencia emocional, se recomienda a las instituciones educativas dedicar espacios para el desarrollo de estas para contribuir a la reducción de dicha problemática.

Con el propósito de dar respuesta a la pregunta que motivó la presente investigación, se halló que los imaginarios de los jóvenes no están alejados de lo planteado por los autores que han estudiado el tema. Solo se encontró un punto de discusión en cuanto a la frecuencia de las acciones, pues los participantes refieren que una acción mal intencionada es suficiente para dejar una huella imborrable en la vida de la víctima, mientras que los autores consideran que debe ser sistemática. Es decir, una sola conducta de agresión por redes sociales (para los chicos) ya es una acción de ciberacoso, mientras que los autores refieren que estos comportamientos deben ser repetitivos.

Por todo lo dicho en este apartado, sería importante replicar este tipo de estudios sobre el ciberacoso en la era digital, pues se determinó que los jóvenes utilizan los artefactos tecnológicos para difundir sus vivencias cotidianas; siendo los eventos negativos, casi siempre, los más visibles. Además, en el rastreo de antecedentes, se detectó la falta de investigaciones de corte cualitativo, necesarias para tener en cuenta la opinión de los jóvenes, quienes, por ser protagonistas de dicha problemática, conocen directamente el tema central de esta investigación, como se pudo evidenciar en el desarrollo de las técnicas de recolección de información. También se observó que están dispuestos a aportar desde su experiencia para la solución de la misma. 


\section{Referencias}

Álvarez, J. (2015). Como hacer investigación cualitativa: fundamentos y metodología. Paidós.

Bermúdez, M. (2004). Déficit de autoestima: evaluación, tratamiento y prevención en la infancia y adolescencia. Pirámide.

Castillo, C. y Pacheco, M. (2008). Perfil del maltrato (buIlying) entre estudiantes de secundaria de la ciudad de Mérida, Yucatán. Revista Mexicana de Investigación Educativa, 13(38), 825-842. http://www.scielo. org.mx/pdf/rmie/v13n38/v13n38a7.pdf

Castorina, A. (2003). Representaciones sociales: problemas reales y conocimientos infantiles. Gedisa.

Corte Constitucional de la República de Colombia (2015). Sentencia T-478. http://legal.legis.com.co/ document?obra=jurcol\&document=jurcol_b7 cf8eOf394542cab76d4fe49a79cc1d

Del Rey, R., Flores, J., Guarmendia, M., Martínez, G., Ortega R. y Tejerina, O. (2010). Protocolo de actuación escolar ante el ciberbullying. https://www. juntadeandalucia.es/educacion/portals/delegate/

Escobar, J., Montoya, L., Restrepo, D. y Mejía, D. (2016). Ciberacoso y comportamiento suicida. ¿Cuál es la conexión? A propósito de un caso. Revista Colombiana de Psiquiatría, 46(4), 247-25. http://www.sciencedirect.com/science/article/pii/ S0034745016300798

Fundación Santillana para Iberoamérica (2012). Agresión escolar: prueba superada. http://www. premiosantillana.com.co/pdf/PREMIO_2012.pdf

Gadamer, H. (1996). Verdad y método fundamentos de una hermenéutica filosófica. Sígueme.

Goleman, D. (1996). La inteligencia emocional. Javier Vergara.

Instituto Interamericano de Derechos Humanos (2014). Prevención del acoso escolar bullying y ciberbullying. https://www.iidh.ed.cr/iidh/media/1573/buIling-2014.pdf

Kowalski, R. y Limber, S. (2013). Physical and Academic Correlates of Cyberbullying and Traditional Bullying. Journal of Adolescent Health, 13, 13-20.
Latorre, A. y Muñoz, E. (2001). Educación para la tolerancia programa de prevención de conductas agresivas y violentas en el aula. Desclee de Brouwer.

Luengo, J. (2011). Ciberbullying. Guía de recursos para centros educativos en caso de ciberacoso. http:// www. madrid.org/bvirtual/BVCM013909.pdf

Martínez, M. (2006). Ciencia y arte en la metodología cualitativa. Trillas.

Morales, T., Serrano. M., Miranda, D. y Santos, A. (2014). Ciberbullying, acoso cibernético y delitos invisibles. Experiencias psicopedagógicas. http://ri.uaemex.mx/ bitstream/handle/20.500.11799/21576/L_515_0.pdf

Nolasco, A. (2012). La empatía y su relación con el acoso escolar. Revista de Estudios y Experiencias en Educación, 11(22), 35-54. http://www.redalyc.org/ pdf/2431/243125410002.pdf

Organización Mundial de la Salud (2016). Informe sobre la situación mundial de la prevención mundial de la violencia 2014. https://oig.cepal.org/sites/default/ files/informe_sobre_la_situacion_mundial_de_la_ prevencion_de_la_violencia.pdf

Pinto, J. (1995). Los imaginarios sociales. La nueva construcción de la realidad social. Sal Terrae.

Quiroz, A., Velásquez, A. García, B. y González, S. (s. f.). Técnicas interactivas para la investigación social cualitativa (pp. 9-114).

Rifkin, J. (2010). La civilización empática. Paidós.

Sanabria, J. (2014). Representaciones sociales del buIlying en estudiantes de grados sextos y séptimos de la Institución Educativa Luis Carlos Galán Sarmiento (trabajo de grado). Universidad Nacional Abierta y a Distancia de Colombia. http://stadium.unad.edu.co/preview/UNAD.php?url=/bitstream/10596/2705/1/1069734785.pdf

Sánchez, L., Crespo, G., Aguilar, R., Bueno, F. Benavent, R. y Valderrama, J. (2016). Los adolescentes y el ciberacoso. http://www.fundacioncsz.org/ArchivosPublicaciones/292.pdf

Sandín, C. (1967). Pedagogía de las emociones. Marfil. Taylor, C. (2006). Imaginarios sociales modernos. Paidós.

\section{()ㅛ $(\Theta 0$}

Esta obra está bajo licencia Creative Commons Atribución-NoComercial-Compartirlgual 4.0 Internacional https://creativecommons.org/licenses/by-nc-sa/4.0/deed.es ISSN 1657-9089 • Vol 19, No 1 (enero-junio 2020). pp. 21-32 